\title{
Tyler, Faecalibacterium and biodiversity
}

\author{
Stephen B Hanauer
}

My wife and I welcomed our first grandchild, Tyler, into the world this week. The emotions are overwhelming. I am not particularly religious, but his arrival is as close as one can come to the concept of one's immortality.

As he and his parents live with a dog (which, my audience may recall, precludes my allergic wife from extended visits to his home), I have hopes that his early exposure to these antigens may prevent subsequent allergies. As a proponent of the hygiene hypothesis - that a lack of early childhood exposure to infectious agents, symbiotic microorganisms (e.g. gut flora), and parasites modulates the development of the immune system and leads to increased susceptibility to allergic diseases - my advice to his parents was to expose him to everything...except processed foods, unnecessary antibiotics and NSAIDs. Happily, he is being breast fed.

I hope that exposing his gut immune system to multiple antigens will create a strong immunoregulatory environment. Perhaps his gut flora will include abundant 'protective' species such as Faecalibacterium prausnitzii, a member of the Clostridium leptum group, levels of which were recently found to be reduced in patients with Crohn's disease and whose absence was associated with an increased risk of postsurgical recurrence of disease (Sokol H et al. [2008] Proc Natl Acad Sci USA 105: 16731-16736).

My grandson, an expansion of our family's gene pool and a mixture of somewhat different backgrounds, will, in his own small way, add to the biodiversity of our planet. As Bernstein and Ludwig point out in relation to the influence of biodiversity on medicine (Bernstein AS and
I... . pray that... generation[s] to come will be able to adapt and prosper by learning how to help prevent, not potentiate the loss of biodiversity...

SB Hanauer is Editorin-Chief of Nature Clinical Practice Gastroenterology \& Hepatology.

\section{Competing interests}

The author declared no competing interests.

www.nature.com/clinicalpractice doi:10.1038/ncpgasthep1351
Ludwig DS [2008] JAMA 300: 2297-2999), "The diversity of life in and on the human body also has considerable relevance to health." In their commentary they refer to the identification of new species in our environment, the relevance of natural products as sources of a wide spectrum of medications, and the risks to public health caused by disruptions of habitats and alterations in environmental and human ecology. They estimate that the number of microbial species on the skin is about 180, with another 700 in the mouth and more than 1,000 in the gastrointestinal tract; their article also notes that gut bacteria have potential effects on food allergies, asthma, eczema, IBD, and obesity. In prior editorials I highlighted that global warming had allowed Vibrio parahemolyticus to grow even in Alaskan oyster beds and contribute to gastroenteritis, and described how substitution of corn products for other crops contributes to obesity. Bernstein and Ludwig describe changes in the epidemiology of Lyme disease caused by disturbances in forests, which has allowed rodent reservoirs for the black-legged tick to outcompete other species, and how changes in human behavior, such as depletion of fish stocks off the west coast of Africa, forced the consumption of bush meats and consequently resulted in exposure to novel retroviral infections similar to HIV.

I am afraid that our descendants will inhabit quite a different planet to the one I was born onto, but pray that my grandson's generation and those to come will be able to adapt and prosper by learning how to help prevent, not potentiate, the loss of biodiversity. 